\title{
MICROSTRUCTURE OBSERVATION AND ELECTRICAL CONDUCTIVITIES OF PROTON-CONDUCTING TiO2-P2O5 GLASS-CERAMIC SOLID ELECTROLYTES
}

\author{
Ryoto Kawamura, Ryosuke Sakamoto, Yoshito Oshima and Junichiro Otomo* \\ (*Corresponding author: otomo@k.u-tokyo.ac.jp)
}

Department of Environment Systems, Graduate School of Frontier Sciences, The University of Tokyo, 5-1-5 Kashiwanoha, Kashiwa, Chiba 277-8563, Japan

Keywords: Proton conductor, Glass-ceramic, Sol-gel synthesis, Interface, Electrical conductivity

\begin{abstract}
A new, fast proton-conducting $\mathrm{TiO}_{2}-\mathrm{P}_{2} \mathrm{O}_{5}$ glass-ceramic was developed and investigated through microstructure observation and electrical conductivity measurements. $\mathrm{TiO}_{2}-\mathrm{P}_{2} \mathrm{O}_{5}$ glass-ceramic samples were prepared by a sol-gel method and post-annealing heat treatment. With an increase in the post-annealing temperature, growth of $\mathrm{TiP}_{2} \mathrm{O}_{7} \mathrm{crystals}$ in the $\mathrm{TiO}_{2}-$ $\mathrm{P}_{2} \mathrm{O}_{5}$ glassy phase was observed. In addition, a tenfold enhancement in maximum conductivity was observed after postannealing heat treatment compared with the as-prepared sample and polycrystalline $\mathrm{TiP}_{2} \mathrm{O}_{7}$. The interfacial layer between the $\mathrm{TiO}_{2}-\mathrm{P}_{2} \mathrm{O}_{5}$ glassy phase and the $\mathrm{TiP}_{2} \mathrm{O}_{7}$ crystal phase may act as a fast proton-conducting path, thereby improving the total conductivity. This hypothesis is discussed using the brick layer model.
\end{abstract}

(Received Sep. 29, 2013; Accepted Nov. 22, 2013)

\section{INTRODUCTION}

The development of alternative power sources is an increasingly important issue for the establishment of a sustainable society with low greenhouse gas emissions. Fuel cell technology is one of the key technologies currently available for power generation systems. Among the various types of fuel cells, solid oxide fuel cells (SOFCs) have the advantage of power generation efficiency. To diminish degradation of the cell and stack due to a high-temperature operation and to achieve long lifetime, lowering the operation temperature of SOFC systems is important. Inorganic proton conductors have high ion conductivity at intermediate temperatures (300-600 ${ }^{\circ} \mathrm{C}$ ) and can provide a solution for the development of next-generation fuel cell systems using protonconducting electrolytes operating at intermediate temperature (p-ITFC: proton-conducting solid electrolyte intermediate temperature fuel cell). $\mathrm{p}$ ITFCs can be used to realize robust systems with high energy conversion efficiency ${ }^{1}$. Therefore, the development of proton-conducting materials is very important. However, as yet, a suitable protonconducting material has not been developed and currently much effort is directed to developing a new proton-conducting electrolyte ${ }^{1-3}$.

In this study, we focus on a phosphorous-oxide based proton conductor. Phosphate glasses have been studied because of their relatively high proton conductivities $^{4-8}$ and are considered as excellent candidate materials for $\mathrm{p}$-ITFC electrolytes. In recent studies, glass-ceramics of phosphorous-oxide materials were also investigated in terms of the influence of the interface between the glassy and crystalline phases on ionic conductivity ${ }^{9-11}$. To improve ion conductivity, controlling the microstructure of the ion conductors, especially the interfacial structure, may be an effective approach ${ }^{9-13}$. We have previously taken this approach to investigate the enhancement of interfacial ion conductivity. In our previous study ${ }^{11}$, we investigated proton conductivity in a mixture of phosphorousoxide glass and pyrophosphate $\left(\mathrm{ZnO}-\mathrm{P}_{2} \mathrm{O}_{5}\right.$ glass and $\mathrm{TiP}_{2} \mathrm{O}_{7}$ crystal) and observed an improvement of proton conductivity, which may have been due to an acceleration effect at the interface between the glassy and crystalline phases. The interfacial proton diffusion paths around pyrophosphate particles may also contribute to the improvement in proton conductivity ${ }^{11}$.

In the present study, we prepared protonconducting glass-ceramics from $\mathrm{TiO}_{2}-\mathrm{P}_{2} \mathrm{O}_{5}$ glass, controlling crystal growth in the glassy phase by post-annealing heat treatment. Through appropriate heat treatment, we demonstrate the formation of the $\mathrm{TiP}_{2} \mathrm{O}_{7}$ crystal phase in the $\mathrm{TiO}_{2}-\mathrm{P}_{2} \mathrm{O}_{5}$ glassy phase and the effect of crystal formation on the enhancement of electrical conductivity. We also show that the maximum conductivity is obtained by controlling the microstructure of the glass-ceramics. In the previous studies, phosphate glasses were prepared by a melt-quenching technique ${ }^{9,10}$, which are performed at relatively high temperature and thereby proton will desorb via dehydration. To keep high proton concentration in prepared glasses, we employed a sol-gel method, which enables us to 
lower temperature in the sample preparation. The present study provides the fundamental information about proton conductivity at interface with controlling the microstructure, considering the application as solid electrolyte working at intermediate temperature in p-ITFC.

\section{MATERIALS AND METHODS}

The following reagents were purchased commercially for the sol-gel synthesis of $\mathrm{TiO}_{2}-\mathrm{P}_{2} \mathrm{O}_{5}$ glasses and were used as received: titanium tetra-ipropoxide ( $\mathrm{Ti}\left(\mathrm{OPr}^{\mathrm{i}}\right)_{4}$, TTIP) (Kanto Chemical, Japan, purity > 97.0\%), titanium tetra-sec-butoxide $\left(\mathrm{Ti}\left(\mathrm{OBu}^{\mathrm{sec}}\right)_{4}\right.$, TTSB) (Kojundo Chemical Laboratory, Japan, purity > 99.999\%), an approximately 1:1 molar mixture of mono- $(\approx 45-55 \%)$ and disubstituted $\quad(\approx 45-55 \%) \quad$ n-butyl phosphate $\left(\mathrm{PO}(\mathrm{OH})\left(\mathrm{OBu}^{\mathrm{n}}\right)_{2}, \quad \mathrm{PO}(\mathrm{OH})_{2}\left(\mathrm{OBu}^{\mathrm{n}}\right), \quad \mathrm{P}-\mathrm{Bu}\right) \quad$ (Santa Cruz Biotechnology, USA), super dehydrated isopropanol ( $\mathrm{Pr}{ }^{\mathrm{i} O H}$ ) (Wako Pure Chemical Industries, Japan, purity $>99.5 \%$ or Kanto Chemical, Japan, purity > 99.7\%), and 2-butanol $\left(\mathrm{Bu}^{\mathrm{sec}} \mathrm{OH}\right)$ (Wako Pure Chemical Industries, purity $>99.0 \%$ ).

The desired amount of TTIP was initially dissolved in super dehydrated $\operatorname{Pr}^{\mathrm{i}} \mathrm{OH}$, typically with a molar ratio of $1: 14$. P-Bu was then added dropwise and the solution was stirred with a magnetic stirrer for $1 \mathrm{~h}$. The resulting mixture was hydrolyzed by adding an aqueous solution consisting of $\mathrm{Pr}^{\mathrm{i}} \mathrm{OH}$ and $\mathrm{Bu}^{\mathrm{sec}} \mathrm{OH}$ dropwise. The typical molar ratio of TTIP $: \mathrm{H}_{2} \mathrm{O}: \mathrm{Pr}^{\mathrm{i} O H}: \mathrm{Bu}^{\mathrm{sec}} \mathrm{OH}$ was 1:4:2.7:2.9. Mixing was performed in a glovebox under a dry nitrogen flow. The prepared sol was poured into a polystyrene case in the glovebox and gelation was allowed to occur at room temperature in air. The resulting gel was aged at room temperature for $\approx 3-7$ weeks. After drying, the gel was placed into an alumina tube and further heated under a pure oxygen flow at $165^{\circ} \mathrm{C}$ for $5 \mathrm{~h}$ and then $295^{\circ} \mathrm{C}$ for $2 \mathrm{~h}$ before being sintered at $480{ }^{\circ} \mathrm{C}$ for $4 \mathrm{~h}$. This heating process was conducted under a pure oxygen flow. During the heating process, solvent, water, and organic compounds were removed. The obtained samples were white, glassy, and lustrous thin pieces (typical size of one edge: $\approx 2-3$ $\mathrm{mm}$; thickness: $0.5-1 \mathrm{~mm})$. The samples were then mechanically ground to powder in an agate mortar for 15 min. The obtained powdered samples were pressed at $5.6 \mathrm{t} \mathrm{cm}^{-2}$ to form dense pellets (diameter: $10 \mathrm{~mm}$, thickness: ca. $1 \mathrm{~mm}$ ). Finally, the pellets were calcined at $\approx 480-700{ }^{\circ} \mathrm{C}$ in air. Au electrodes were attached to both sides of the pellets using a quick coater (SC-701; Sanyu Denshi, Tokyo, Japan).

The pellet samples were placed in a quartz tube and dry Ar gas was supplied through the tube at atmospheric pressure. Conductivity measurements were obtained using ac impedance spectroscopy with a Hewlett Packard 4192A impedance analyzer in the frequency range from $10 \mathrm{MHz}$ to $10 \mathrm{~Hz}$.

To characterize the specimens, X-ray diffraction (XRD) (Rigaku SmartLab, Tokyo, Japan) patterns were recorded at room temperature using a $\mathrm{Cu} \mathrm{K} \alpha$ radiation source. Raman spectroscopy was also conducted for the $\mathrm{TiO}_{2}-\mathrm{P}_{2} \mathrm{O}_{5}$ glass-ceramic samples using a micro-Raman spectrometer (LabRAM1B; Horiba-JobinYvon, Kyoto, Japan) with a continuous wave $\mathrm{He}-\mathrm{Ne}$ laser beam at $632 \mathrm{~nm}$ and a CCD detector. Microstructures of $\mathrm{TiO}_{2}-\mathrm{P}_{2} \mathrm{O}_{5}$ glass and the glass-ceramics after post-annealing heat treatment were observed by transmission electron microscopy (TEM) (JEOL-2100; JEOL Ltd., Tokyo, Japan) and energy dispersive X-ray spectroscopy (TEM-EDX) (JEOL-2010F; JEOL Ltd.).

\section{RESULTS AND DISCUSSION}

Characterization of $\mathrm{TiO}_{2}-\mathrm{P}_{2} \mathrm{O}_{5}$ glass-ceramics

Typical XRD patterns after heat treatment at different temperatures are shown in Fig. 1. The asprepared sample that was heated at $480^{\circ} \mathrm{C}$ was mostly amorphous, although small amounts of titanium pyrophosphate, $\mathrm{TiP}_{2} \mathrm{O}_{7}$, also formed. The broad peak between $15-35^{\circ}$, i.e., halo peak, may originate from phosphate glass.

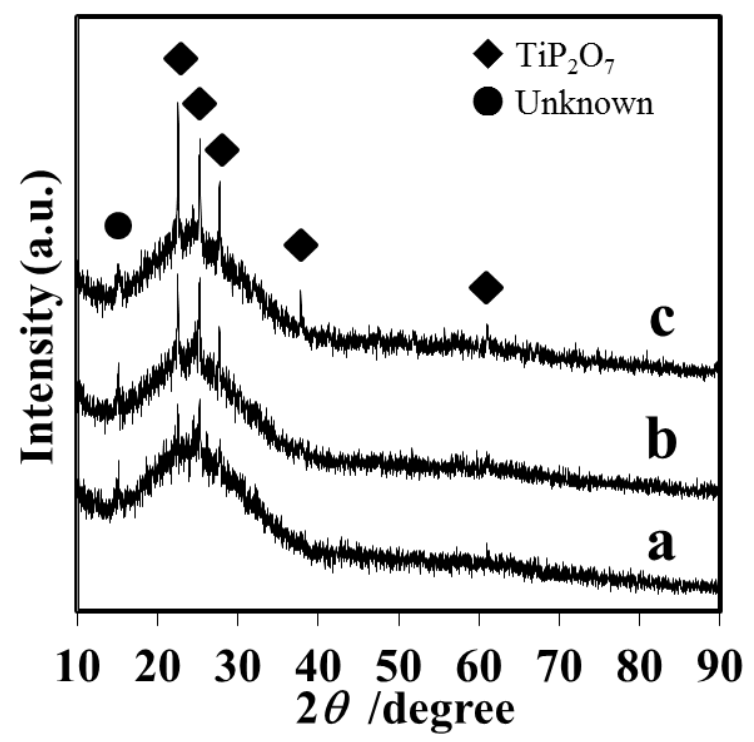

FIGURE 1. XRD patterns of $\mathrm{TiO}_{2}-\mathrm{P}_{2} \mathrm{O}_{5}$ glassceramic samples after various heat treatments. a) asprepared $\left(480{ }^{\circ} \mathrm{C}\right)$; and after post-annealing heat treatment at b) $590{ }^{\circ} \mathrm{C}$ and c) $700{ }^{\circ} \mathrm{C}$.

Increasing the post-annealing temperature up to $700{ }^{\circ} \mathrm{C}$, the $\mathrm{TiP}_{2} \mathrm{O}_{7}$ peak became larger: $\mathrm{TiP}_{2} \mathrm{O}_{7}$ crystal phase was grown in $\mathrm{TiO}_{2}-\mathrm{P}_{2} \mathrm{O}_{5}$ glass. This result shows that $\mathrm{TiO}_{2}-\mathrm{P}_{2} \mathrm{O}_{5}$ glass-ceramics (i.e., the 
composite of the $\mathrm{TiO}_{2}-\mathrm{P}_{2} \mathrm{O}_{5}$ glassy phase and the $\mathrm{TiP}_{2} \mathrm{O}_{7}$ crystal phase) can be successfully prepared under these conditions.

Raman spectra of the samples heat treated at 550, 560, 580, and $600{ }^{\circ} \mathrm{C}$ are shown in Fig. 2. As the temperature increases, the broad signal becomes sharp. The Raman bands were assigned based on previous studies ${ }^{14-17}$. The main bands are attributed to $\mathrm{TiP}_{2} \mathrm{O}_{7}{ }^{14}$. In addition, very weak signals originating from anatase $\mathrm{TiO}_{2}{ }^{15,16}$ were observed at around 520 and $650 \mathrm{~cm}^{-1}$ at temperatures higher than $580^{\circ} \mathrm{C}$. The observed spectra suggest that $\mathrm{TiP}_{2} \mathrm{O}_{7}$ crystal growth mainly occurs through annealing of the $\mathrm{TiO}_{2}-\mathrm{P}_{2} \mathrm{O}_{5}$ glass-ceramics accompanied by the formation of a small amount of $\mathrm{TiO}_{2}$.

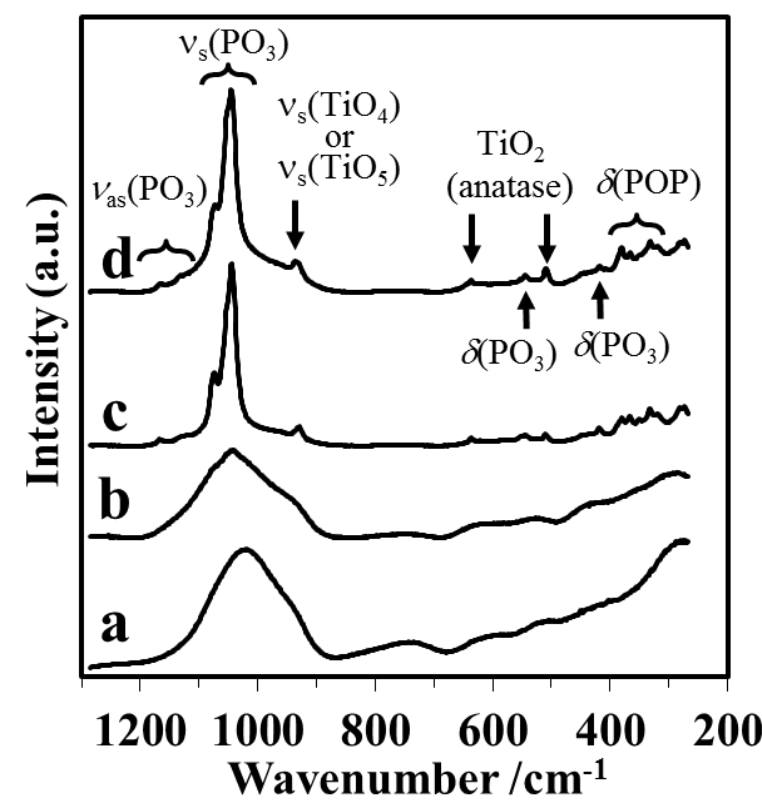

FIGURE 2. Raman spectra of the $\mathrm{TiO}_{2}-\mathrm{P}_{2} \mathrm{O}_{5}$ glassceramic samples after post-annealing heat treatment at: a) $550{ }^{\circ} \mathrm{C}$, b) $560{ }^{\circ} \mathrm{C}$, c) $580{ }^{\circ} \mathrm{C}$, and d) $600{ }^{\circ} \mathrm{C}$.

\section{Microstructure of $\mathrm{TiO}_{2}-\mathrm{P}_{2} \mathrm{O}_{5}$ glass-ceramics}

To observe the microstructural changes of the $\mathrm{TiO}_{2}-\mathrm{P}_{2} \mathrm{O}_{5}$ glass-ceramics subjected to different heat treatment conditions, TEM images were analyzed and are shown in Fig. 3. For the as-prepared sample treated at $480{ }^{\circ} \mathrm{C}$ without post-annealing treatment, a small crystal, less than $5 \mathrm{~nm}$ in diameter, is observed in the $\mathrm{TiO}_{2}-\mathrm{P}_{2} \mathrm{O}_{5}$ glassy phase (Fig. 3a). Considering the XRD patterns, these small particles can be assumed to be $\mathrm{TiP}_{2} \mathrm{O}_{7}$. After post-annealing treatment at $600{ }^{\circ} \mathrm{C}$, significant crystal growth was observed. The diameter of the $\mathrm{TiP}_{2} \mathrm{O}_{7}$ particles reached approximately $100 \mathrm{~nm}$. These TEM images clearly show that the $\mathrm{TiP}_{2} \mathrm{O}_{7}$ crystal phase is surrounded by the $\mathrm{TiO}_{2}-\mathrm{P}_{2} \mathrm{O}_{5}$ glassy phase. To investigate the details of the composite structure, TEM-EDX measurements were performed, in particular, focusing on the interface between the $\mathrm{TiO}_{2}-\mathrm{P}_{2} \mathrm{O}_{5}$ glassy phase and the $\mathrm{TiP}_{2} \mathrm{O}_{7}$ crystalline phase. Elemental analysis was conducted by line-scanning from point A to point B, as shown in Fig. 4, which marks the transition from the glassy phase to the crystalline phase. The boundary between the two phases was analyzed by the morphological change in the image. As previously discussed, if the interfacial layer between the glassy and crystalline phases acts as a fast protonconducting path, spatial deviation of elements such as $\mathrm{Ti}, \mathrm{P}$, and $\mathrm{O}$ around the interfacial layer might occur. The present elemental analysis of $\mathrm{Ti}, \mathrm{P}$, and $\mathrm{O}$ suggests that there was no deviation of the elements or segregation between the glassy and crystalline phases.

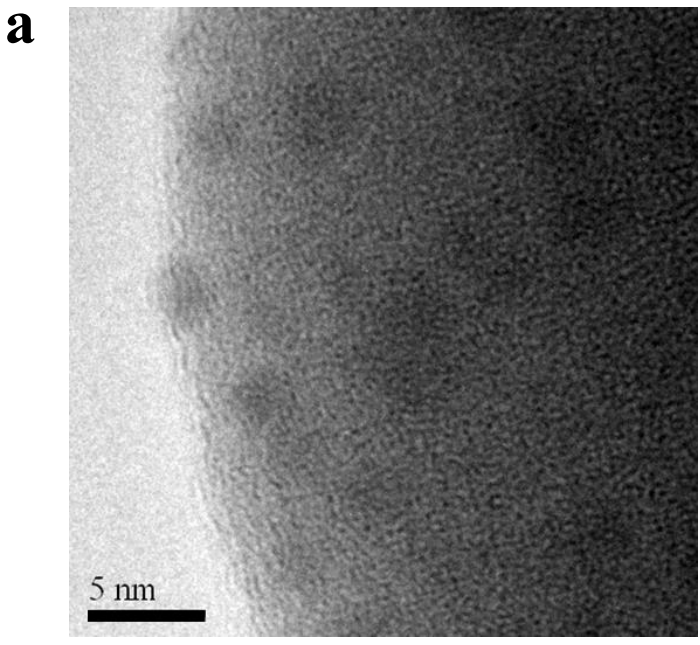

b

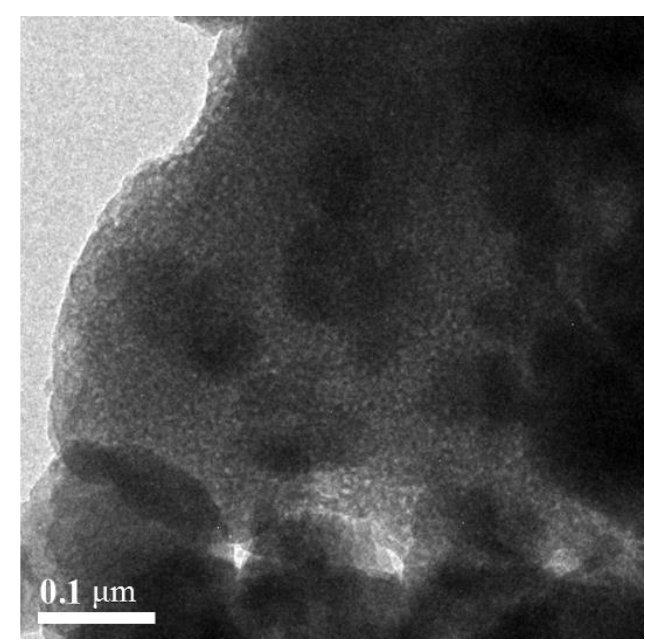

FIGURE 3. TEM images of $\mathrm{TiO}_{2}-\mathrm{P}_{2} \mathrm{O}_{5}$ glass-ceramic samples after heat treatment at different temperatures: a) as-prepared sample $\left(480{ }^{\circ} \mathrm{C}\right)$ scale bar: $5 \mathrm{~nm}$; b) post-annealing heat treated at $600{ }^{\circ} \mathrm{C}$, scale bar: 100 nm. 
$\mathbf{a}$

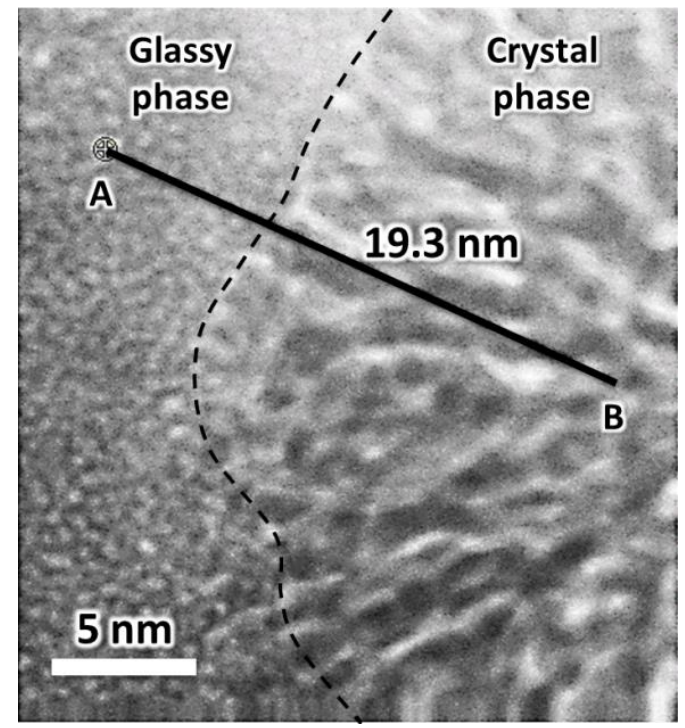

b

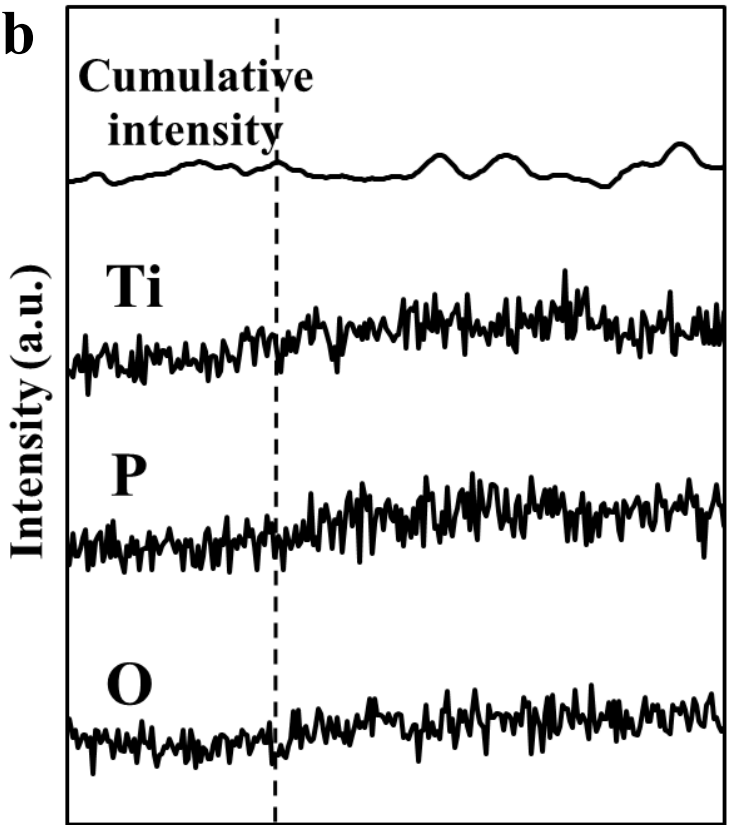

(A)

(B)

FIGURE 4. TEM-EDX analysis of the interface between the $\mathrm{TiO}_{2}-\mathrm{P}_{2} \mathrm{O}_{5}$ glassy phase and the $\mathrm{TiP}_{2} \mathrm{O}_{7}$ crystalline phase after post-annealing heat treatment at $600{ }^{\circ} \mathrm{C}$. a) TEM images. Line-scanning was conducted from point A to point B. The broken line represents the boundary between the glassy and crystalline phases. b) EDX signals obtained by linescanning from point A to point B. The broken line represents the boundary position.

\section{Electrical conductivities in $\mathrm{TiO}_{2}-\mathrm{P}_{2} \mathrm{O}_{5}$ glass-ceramics}

The influence of post-annealing heat treatment on electrical conductivity in the $\mathrm{TiO}_{2}-\mathrm{P}_{2} \mathrm{O}_{5}$ glass-

ceramics was investigated (Fig. 5). The electrical conductivity was found to be significantly influenced by the post-annealing temperature, whereas the activation energy, $\Delta E_{\mathrm{a}}$, was not influenced by the post-annealing temperature. The values of $\Delta E_{\mathrm{a}}$ in Fig. 5 were approximately $65 \mathrm{~kJ} / \mathrm{mol}$. According to previous studies, the values of $\Delta E_{\mathrm{a}}$ for phosphate glasses, $\mathrm{MO}-\mathrm{P}_{2} \mathrm{O}_{5}(\mathrm{M}=\mathrm{Ca}, \mathrm{Mg}, \mathrm{Be}, \mathrm{Ba}$ and $\mathrm{Sr})$, which were prepared by a melt-quenching technique, were $105-125 \mathrm{~kJ} / \mathrm{mol}^{4,8}$, while the value of $\Delta E_{\mathrm{a}}$ for polycrystalline $2 \% \mathrm{Al}$-doped $\mathrm{TiP}_{2} \mathrm{O}_{7}$ was $68 \mathrm{~kJ} / \mathrm{mol}^{18}$. The present value is rather close to that of Al-doped $\mathrm{TiP}_{2} \mathrm{O}_{7}$. The value indicates the barrier of proton diffusion process. The results suggest that $\Delta E_{\text {a }}$ depends on preparation method, heat treatment and resultant microstructure of the samples. Because the electrical conductivity is expected to have a maximum value under optimum conditions, this was measured as a function of post-annealing temperature to further investigate the effect of heat treatment; the results are shown in Fig. 6.

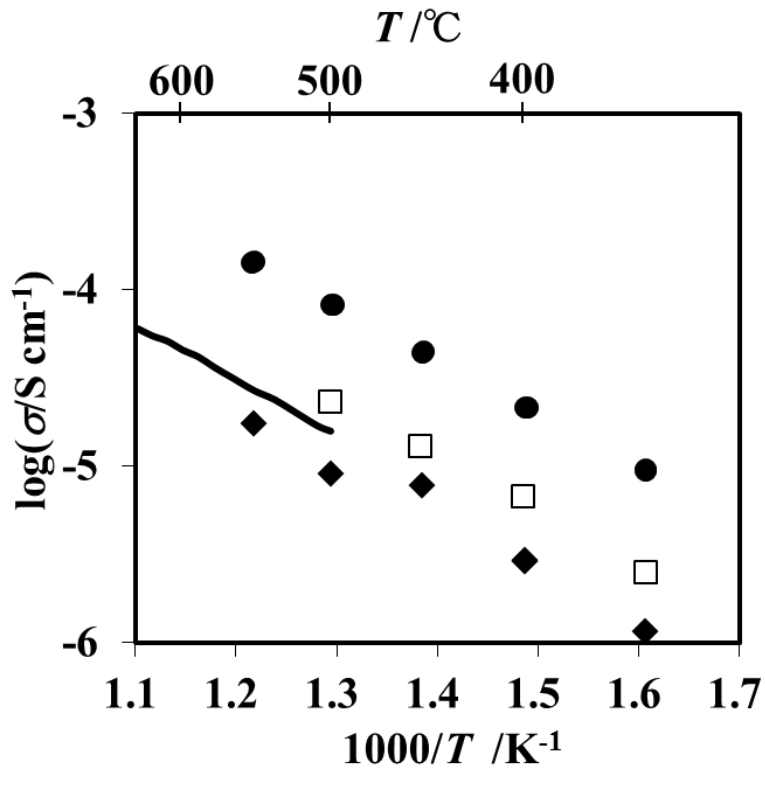

FIGURE 5. Temperature dependence of the electrical conductivity (measured in a dry Ar flow) of $\mathrm{TiO}_{2}-$ $\mathrm{P}_{2} \mathrm{O}_{5}$ glass-ceramics subjected to post-annealing heat treatment at different temperatures: $\square: 480{ }^{\circ} \mathrm{C}$; $550{ }^{\circ} \mathrm{C}$; $595{ }^{\circ} \mathrm{C}$. Solid line: reported value of polycrystalline $\mathrm{TiP}_{2} \mathrm{O}_{7}{ }^{14}$.

The electrical conductivity is plotted in Fig. 6 as a function of post-annealing temperature at a fixed measurement temperature of $450^{\circ} \mathrm{C}$. The electrical conductivity increases with an increase in postannealing temperature, reaching a maximum at $\approx 530-550^{\circ} \mathrm{C}$. At higher temperatures, the conductivity decreases. The conductivity measured for a post-annealing temperature of $600^{\circ} \mathrm{C}$ 
approximates the reported value for polycrystalline $\mathrm{TiP}_{2} \mathrm{O}_{7}{ }^{18}$. The maximum conductivity was approximately ten times higher than that of the asprepared sample and $\mathrm{TiP}_{2} \mathrm{O}_{7}$. The result suggests that an optimum microstructure of the $\mathrm{TiO}_{2}-\mathrm{P}_{2} \mathrm{O}_{5}$ glassceramic exists, at least in terms of its conductive properties. We suggest, based on these results that the formation of $\mathrm{TiP}_{2} \mathrm{O}_{7}$ particles in $\mathrm{TiO}_{2}-\mathrm{P}_{2} \mathrm{O}_{5}$ glass may contribute to the improvement of proton conductivity. Additionally, the relatively high conductivity observed in this work may also be realized by a solgel method. The present samples were prepared at lower temperatures in comparison with a meltquenching technique. Although any direct evidences are not obtained, such low preparation temperature can contribute to retain high proton concentration in the present samples.

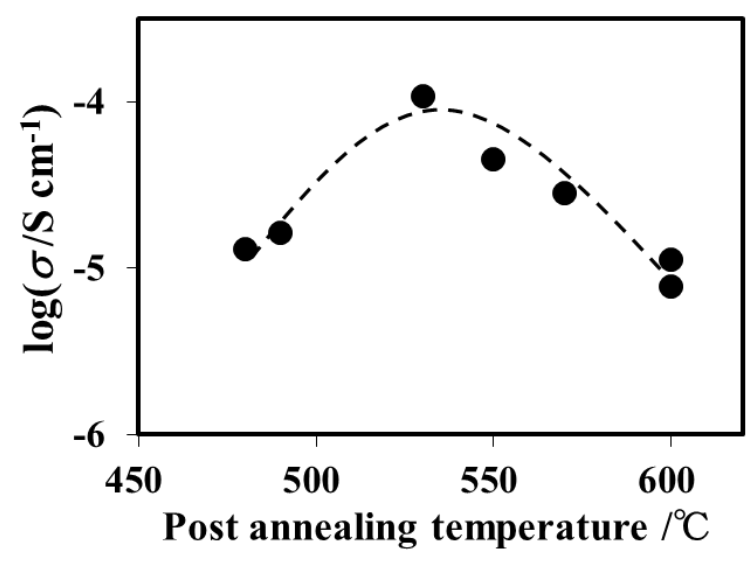

FIGURE 6. Electrical conductivity of $\mathrm{TiO}_{2}-\mathrm{P}_{2} \mathrm{O}_{5}$ glass-ceramics as a function of post-annealing temperature. The electrical conductivity was measured at a fixed temperature of $450{ }^{\circ} \mathrm{C}$ and under Ar flow.

A plausible explanation for the improvement of proton conductivity is the fast proton transport along the interface between the $\mathrm{TiO}_{2}-\mathrm{P}_{2} \mathrm{O}_{5}$ glassy phase and the $\mathrm{TiP}_{2} \mathrm{O}_{7}$ crystalline phase. A recent study ${ }^{18}$ has rejected fast proton transport in polycrystalline $\mathrm{TiP}_{2} \mathrm{O}_{7}$. During heat treatment, the interface is generated by crystal growth of the $\mathrm{TiP}_{2} \mathrm{O}_{7}$ grains. We roughly evaluated the influence of interfacial conductivity in $\mathrm{TiO}_{2}-\mathrm{P}_{2} \mathrm{O}_{5}$ glass-ceramic on the total conductivity using a brick layer model ${ }^{19}$. The interfacial admittance, $\widehat{Y}_{\mathrm{i}}$, can be estimated by the following equation.

$$
\begin{aligned}
& \hat{Y}_{\mathrm{i}}=\hat{Y}_{\text {glass-ceramics }}-\hat{Y}_{\text {bulk }} \\
& \quad=\hat{\sigma}_{\mathrm{i}}\left\{\frac{(2 D+d) d}{D+d}\right\} f_{\mathrm{i}} \\
& 1 / \hat{Y}_{\text {bulk }}=\hat{Z}_{\text {bulk }}=(1-x) \hat{Z}_{\text {glass }}+x \hat{Z}_{\text {ceramics }}
\end{aligned}
$$

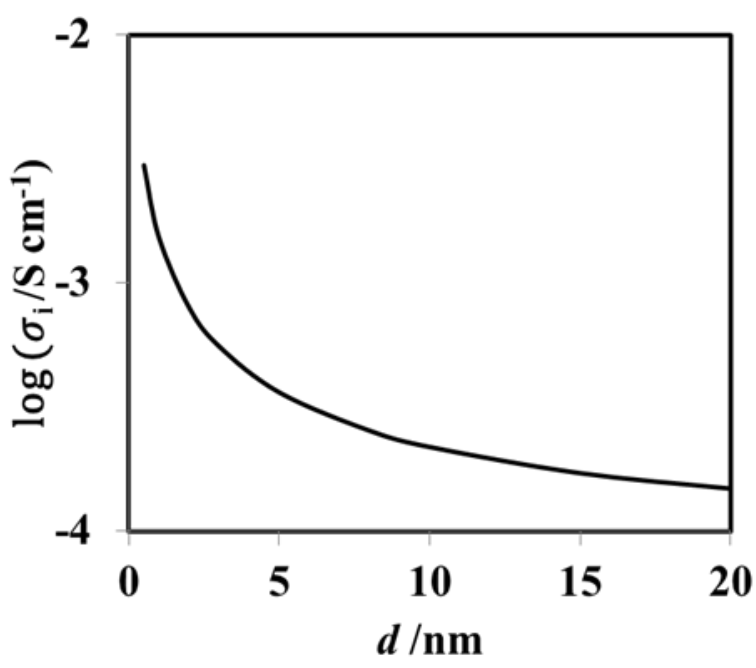

FIGURE 7. Estimated interfacial conductivity in $\mathrm{TiO}_{2}-\mathrm{P}_{2} \mathrm{O}_{5}$ glass-ceramic as a function of the thickness of the interfacial layer. The sample was subjected to post-annealing heat treatment at $550{ }^{\circ} \mathrm{C}$ and measurements were conducted at $450{ }^{\circ} \mathrm{C}$. The volume fraction of crystallite: $x=0.32$.

The glass-ceramic consists of glass and crystalline grains with diameter, $D$, and an interfacial layer between the glass and crystal phases of thickness, $d$. In Eq. $1, \hat{\sigma}_{\mathrm{i}}$ represents the interfacial ac conductivity. The volume fraction, $x$, in Eq. 2 was determined by crystallinity estimated by XRD peak intensity. If it is supposed that the real part of the impedance at $1 \mathrm{kHz}$ corresponds to dc conductivity, $\hat{Z}_{\text {bulk }}$ can be calculated from the conductivity of $\mathrm{TiO}_{2}-\mathrm{P}_{2} \mathrm{O}_{5}$ glass and $\mathrm{TiP}_{2} \mathrm{O}_{7}$ ceramics to obtain a value of interfacial conductivity. Figure 7 shows the interfacial conductivity according to Eq. 1 as a function of the thickness of the interfacial layer for the sample heat treated at $550^{\circ} \mathrm{C}$. Assuming $d$ is between 1 and $20 \mathrm{~nm}$, $\hat{\sigma}_{\mathrm{i}}$ is $\approx 10^{-2.5}-10^{-4} \mathrm{~S} / \mathrm{cm}$, which is $\approx 10-400$ times higher than that of the $\mathrm{TiP}_{2} \mathrm{O}_{7}$ ceramic. In previous studies ${ }^{18,20}$, there is discordance in the reported values for proton conductivity in polycrystalline $\mathrm{TiP}_{2} \mathrm{O}_{7}$. Thus, in light of our results, this discordance might be because of surface or interfacial proton diffusion on $\mathrm{TiP}_{2} \mathrm{O}_{7}$ particles. Although the model of Eq. 1 is one possible mechanism of conductivity enhancement, the microstructural observations (in terms of the spatial elemental distribution) of the glass-ceramics do not provide clear evidence for fast proton transport in the interfacial layer. If segregation at the interfacial layer, e.g., formation of phosphorusrich layer between glassy and crystal phases, would occur, fast proton transport can be induced. In that case, however, the interfacial layer might be finer than the resolution of the present microstructural observation. Further fine microstructural observation 
will be needed. As another possibility, the change of Ti-O-P bonding structure in the interfacial layer can influence proton conductivity. In fact, it has been suggested that proton conductivity in phosphate glasses strongly depends on the state of non-bridging oxygen of $\mathrm{P}=\mathrm{O}^{8}$. Thus, there is a possibility that nonbridging oxygen can be modulated in the interfacial layer when creation of crystalline grains proceeds in the glass-ceramics, thereby increasing proton conductivity. Such hypothesis should be investigated in detail through the observations of proton concentration and Ti-O-P bonding structure in the interfacial layer. This will be the focus of our future research

\section{CONCLUSION}

Proton-conducting $\quad \mathrm{TiO}_{2}-\mathrm{P}_{2} \mathrm{O}_{5}$ glass-ceramics were prepared by a sol-gel method and subsequent post-annealing heat treatment. The microstructure of the $\mathrm{TiO}_{2}-\mathrm{P}_{2} \mathrm{O}_{5}$ glass-ceramics was investigated by TEM, which revealed that $\mathrm{TiP}_{2} \mathrm{O}_{7}$ crystal grains were surrounded by a $\mathrm{TiO}_{2}-\mathrm{P}_{2} \mathrm{O}_{5}$ glassy phase. Elemental analysis of $\mathrm{Ti}, \mathrm{P}$, and $\mathrm{O}$ was also performed using TEM-EDX. The result suggested that there was no deviation of the elements or segregation between the glassy phase and the crystalline phase. The electrical conductivity in the $\mathrm{TiO}_{2}-\mathrm{P}_{2} \mathrm{O}_{5}$ glass-ceramics was examined under dry conditions and was found to be strongly influenced by the post-annealing temperature. The maximum conductivity value was observed for the sample treated at around $530{ }^{\circ} \mathrm{C}$. To understand the conductivity enhancement, the brick layer model was employed with the assumption that the interface between the $\mathrm{TiO}_{2}-\mathrm{P}_{2} \mathrm{O}_{5}$ glassy phase and the $\mathrm{TiP}_{2} \mathrm{O}_{7}$ crystalline phase plays a key role in the highly proton-conducting layer. The brick layer model was found to be valid when an appropriate thickness of the interfacial layer was assumed. Although the detailed mechanism remains unclear, the obtained results provide a strategy for the fabrication of fast proton-conducting materials.

\section{ACKNOWLEDGMENTS}

This work was partly supported by a Grant-in-Aid for Scientific Research (B) (25281061) from the Japan Society of the Promotion of Science, which is greatly appreciated. The authors also thank the Materials Design and Characterization Laboratory, Institute for Solid State Physics, The University of Tokyo, for use of the XRD and TEM facilities.

\section{REFERENCES}

1. E. Fabbri, D. Pergolesi, E. Traversa, Chem. Soc. Rev.,. 39, 4355 (2010).

2. T. Norby, Solid State Ionics, 125, 1 (1999).

3. K.D. Kreuer, Annu. Rev. Mater. Res., 33, 333 (2003).

4. Y. Abe, H. Shimakawa L.L. Hench, J. Non-Cryst. Solids, 51, 357 (1982).

5. H. Hosono, T. Kamae, Y. Abe, J. Am. Ceram. Soc., 12, 294 (1989).

6. Y. Abe M. Hayashi, T. Iwamoto, H. Sumi, L.L. Hench, J Non-Cryst. Solids, 3512138 (2005).

7. K. Imaeda, Y. Minami, M. Sakurai, M. Watanabe, Phos. Res. Bull., 22, 22 (2008).

8. Y. Takamatsu, Y. Daiko, S. Kohara, K. Suzuya, A. Mineshige, T. Yazawa, Solid State Ionics, 245-246, 19 (2013).

9. K. Amezawa T. Tomiga, N. Yamamoto, T. Hanada, Y. Tomii, J. Am. Ceram. Soc., 88, 3211 (2005).

10. G. Zhang, R. Yu, S. Vyas, J. Stettler, J. A. Reimer, G. Harley, L. C. De Jonghe, Solid State Ionics 178, 1811 (2008).

11. Y. Furuhashi, I. Shimada, J. Otomo, Y. Oshima, Mater. Chem. Phys. 127, 322 (2011).

12. S. Adams, K. Hariharan, J. Maier, Solid State Ionics 75, 193 (1995).

13. R.S. Gedam and V.K. Deshpande, Solid State Ionics 177, 2589 (2006).

14. S. Loridant, I. C. Marcu G. Bergeret and J. M. M. Millet, Phys. Chem. Chem. Phys. 5, 4384 (2003).

15. T. Ohsaka, F. Izumi, Y. Fujiki, J. Raman Spectrosc. 7, 321 (1978).

16. L.A. Farrow, E.M. Vogel, J. Non-Crystal. Solids 143, 59 (1992).

17. A.M.B. Silva, R.N. Correia, J.M.M. Oliveira, M.H.V. Fernandes, J. Euro. Ceram. Soc., 30, 1253 (2010).

18. V. Nalini, R. Haugsrud, T. Norby, Solid State Ionics 181, 510 (2010).

19. S. Murugavel, B. Roling, Physics and Chemistry of glasses 45, (2004) 134-137.

20. M. Nagao, T. Kamiya, P. Heo, A. Tomita, T. Hibino, Mitsuru Sano, J. Electrochem. Soc. 153, A1604 (2006). 